\title{
A paisagem cultural e as novas possibilidades para a atividade familiar rural
}

\author{
Cultural landscape and the new possibilities for familiar rural activity
}

\author{
Douglas Emerson Deicke Heidtmann Junior ${ }^{\mathrm{I}}$ Carlos Loch $^{\mathrm{II}}$
}

\section{RESUMO}

$O$ reconhecimento do patrimônio pelo conceito de paisagem cultural já é difundido na Europa pela Convenção da UNESCO de 1992, mas ainda é recente no Brasil, com a chancela do IPHAN em 2009 e sua aplicação em 2011, nos núcleos rurais de imigração alemã de Rio da Luz e Testo Alto, em Santa Catarina. Este estudo tem o objetivo de evidenciar alternativas para a gestão de tal área, e os resultados, obtidos através da metodologia de apoio à decisão (MCDA-C), aplicada à Superintendência do IPHAN, apontam a continuidade da atividade familiar rural como fundamental para que a paisagem cultural seja preservada e valorizada.

Palavras-chave: paisagem cultural, indicação geográfica, agroindústria familiar rural.

\section{ABSTRACT}

The cultural heritage recognition through the concept of cultural landscape is already widespread in Europe since 1992 UNESCO Convention, but it is recent in Brazil, with the label created by IPHAN in 2009 and its implementation in 2011, in the rural german immigration areas called Rio da Luz and Testo Alto, in Santa Catarina. This study aims to show alternatives for the management of these areas and the results obtained through the multicriteria methodology for decision aiding $(M C D A-C)$ applied with IPHAN managers demonstrate the continuity of rural family activity as fundamental for the cultural landscape preservation.

Key words: cultural landscape, geographical indication, rural family agroindustry.

\section{INTRODUÇÃOO}

O tema da preservação do patrimônio cultural pode parecer estranho às áreas de conhecimento normalmente relacionadas ao estudo do espaço rural. Entretanto, uma nova abordagem dos organismos internacionais de preservação, quanto ao reconhecimento e à valorização do patrimônio através da categoria paisagem cultural tem demonstrado a necessidade de pesquisas que relacionem tal tema ao espaço rural.

É nesse contexto que surge o estudo da área e o artigo que tem como objetivo evidenciar os resultados alcançados pela aplicação de princípios e procedimentos metodológicos da teoria de apoio à decisão (ENSSLIN et al., 2010), junto aos decisores (Superintendência do IPHAN -Instituto do Patrimônio Histórico e Artístico Nacional), como subsídio para a gestão de paisagens culturais.

A categoria de paisagem cultural foi criada pela UNESCO em 1992, para a inscrição de áreas ao redor do mundo que representem as obras combinadas do homem e da natureza e que sejam ilustrativas da evolução da sociedade humana ao longo do tempo, passando a serem protegidas como Patrimônio da Humanidade (UNESCO, 1992). No Brasil, o emprego de tal conceito ainda está em fase embrionária e representa um grande campo de pesquisa e de mercado relacionado, principalmente com o meio rural, pois em vários aspectos ele facilita a valorização da identidade territorial em programas de desenvolvimento.

Procurando empregar o conceito de paisagem cultural no Brasil, o IPHAN publicou, no

\footnotetext{
'Departamento de Arquitetura e Urbanismo, Universidade do Estado de Santa Catarina (UDESC), 88790-000, Laguna, SC, Brasil. E-mail: douglasemerson@gmail.com. Autor para correspondência.

"Universidade Federal de Santa Catarina (UFSC), Florianópolis, SC, Brasil. 
Diário Oficial da União de 05 de maio de 2009, a Portaria 127, de 30 de abril de 2009 que estabelece a chancela da Paisagem Cultural Brasileira - porção peculiar do território nacional, representativa do processo de interação do homem com o meio natural, à qual a vida e a ciência humana imprimiram marcas ou atribuíram valores (BRASIL, 2009). Busca-se aqui lançar uma reflexão sobre as novas possibilidades para a gestão de uma área de caráter rural, englobando as localidades de Testo Alto, no município de Pomerode e de Rio da Luz no município de Jaraguá do Sul, ambas em Santa Catarina, reconhecida no dia 3-052011 como a primeira Paisagem Cultural Brasileira. Tais áreas rurais ainda apresentam elementos trazidos pelos imigrantes germânicos, principalmente, o modelo de ocupação teritorial, a arquitetura e a produção artesanal de alimentos. Ao longo da história, um processo marcado pela descapitalização dos agricultores familiares, êxodo rural e pela conjuntura ditada pelos grandes grupos agroindustriais que exigem escala de produção e padrões sanitários cada vez mais restritivos, demonstrou a necessidade do fortalecimento da agricultura familiar, da revalorização das paisagens rurais e da busca de estratégias alternativas de geração de renda no espaço rural, para as quais podem contribuir as iniciativas de preservação do patrimônio, como a paisagem cultural. Entretanto, as áreas estudadas estão sujeitas a pressões de desenvolvimento, na maioria das vezes, sem considerar os valores históricos e culturais. Pomerode, por exemplo, situa-se muito próximo a municípios que disparam em crescimento (tomando como base a Região Metropolitana do Vale do Itajaí, de acordo com a Lei Complementar Estadual de Santa Catarina 495 de 2010) o que promove "transformações do espaço agrário contemporâneo que têm se caracterizado pelo transbordamento do urbano sobre o rural" (NEUMANN \& LOCH, 2002) tornando-se um incentivo a pesquisas sobre o modelo de desenvolvimento mais adequado.

Particularmente, quanto à produção artesanal de alimentos, destaca-se o caso do queijo cozido (kochkaese, em alemão) que é produzido a partir de uma receita transmitida de geração em geração nas áreas de imigração alemã em Santa Catarina. O IPHAN, juntamente com a EPAGRI (Empresa de Pesquisa Agropecuária e Extensão Rural de Santa Catarina) e as Secretarias de Agricultura da região, tem se mobilizado para proteger o alimento e sua receita como patrimônio cultural nacional, mas a Vigilância Sanitária fiscaliza e restringe a comercialização do produto. Isto ocorre devido à preocupação com a segurança alimentar dos consumidores finais, pois o kochkaese tradicional é feito a partir de leite cru, sendo este o ponto chave para toda a clandestinidade deste produto, cujo costume de preparo torna-se cada vez mais raro na área rural dos municípios.

No caso da preservação e valorização do kochkaese, entra em jogo aquilo que a literatura chama de especialização produtiva familiar, (SULZBACHER et al., 2009) em que uma atividade econômica (a unidade de processamento artesanal de alimentos), pode incorporar em seu escopo um conjunto de atividades de natureza diferente: produzir matéria-prima, processar alimentos, comercializar seus produtos e gerenciar nos aspectos econômicos e financeiros todas estas atividades de forma integrada, podendo chegar até à comercialização, conformando um modelo de desenvolvimento rural que incorpora a noção de território e pulveriza diferentes atividades, com diferentes atores e redes sociais vinculadas. Entretanto, a adoção de tal modelo, não assegura a preservação do Patrimônio Imaterial conforme padrões reconhecidos internacionalmente, visto que o fato de tornar-se proprietário de algum empreendimento (seja turístico, agroindustrial, artesanal, etc.) exige habilidades que nem sempre estão ao alcance dos sujeitos rurais e, quando estão, contribuem para a sua progressiva especialização produtiva, já que vêm aliadas a outras tantas exigências que, progressivamente, estimulam a dedicação exclusiva a tal atividade (SULZBACHER \& DAVID, 2008).

Essa nova forma de especialização produtiva, ao requerer um conjunto de conhecimentos e habilidades que podem transformar o agricultor em um empresário especializado que explora ao máximo a força de trabalho familiar a fim de compensar a falta de capital e de tecnologia, tende a promover uma série de impactos sociais que ainda não estão sendo considerados nos trabalhos que enfocam o desenvolvimento territorial rural. Evidencia-se que na conjuntura atual, os sujeitos rurais podem passar a buscar estratégias ligadas ao seu saber-fazer dentre as quais a produção artesanal de alimentos que passou a ser conhecida como agroindústria familiar (SULZBACHER et al., 2009) e tem se consolidado como uma possibilidade de agregar valor, gerar renda e empregar força de trabalho.

Os limites e potencialidades desta atividade na promoção do desenvolvimento rural têm sido alvo de diversos estudos acadêmicos, sendo que, para o enfoque dado no presente estudo cabe ressaltar o enfrentamento de um ambiente institucional restritivo a este novo leque de atividades, o que implica na 
necessidade de regularizar e estabelecer padrões mínimos de qualidade (SULZBACHER et al., 2009) como aqueles exigidos pela Vigilância Sanitária no caso do Kochkaese.

As limitações colocadas pelo ambiente institucional para legalização, o controle de qualidade e as exigências legais são consideradas no presente estudo como um espaço para a construção de ações sob uma abordagem preservacionista, de valorização da produção familiar rural e de caracterização de produtos alimentares a partir de especificidades locais que podem ser alcançadas pelos resultados da pesquisa aqui empreendida.

\section{MATERIAL E MÉTODOS}

Através do presente trabalho foi construído um modelo para avaliar o desempenho da gestão da paisagem cultural. Trata-se de um estudo de caso, caracterizando-se como exploratório de natureza prática que segue uma abordagem qualiquantitativa, tendo como instrumentos para a coleta de dados entrevistas semiestruturadas com o gestor da Superintendência do IPHAN em Santa Catarina, responsável pelas iniciativas envolvendo as duas áreas chanceladas em nível nacional, complementado por análise documental de relatórios de viagem dos técnicos do IPHAN às áreas estudadas. O instrumento utilizado foi a metodologia multicritério de apoio à decisão construtivista MCDA-C (multicriteria methodology for decision aiding) que possibilitou identificar, organizar, mensurar e integrar os critérios, permitindo à Superintendência visualizar o perfil de desempenho nos critérios identificados por ela para a gestão da paisagem cultural.

O método foi aplicado utilizando-se entrevistas semiestruturadas com o gestor (tomador de decisão), atualmente responsável pelo assunto paisagem cultural no Iphan-SC, de fevereiro a outubro de 2012, com encontros semanais de duração de 2 horas. Além disso, incorporaram-se ao modelo alguns critérios que o gestor do IPHAN levantou em reuniões com a EPAGRI, ocorridas no mesmo periodo da pesquisa e nas foram discutidos temas relacionados à agroindústria familiar e à preservação do patrimônio imaterial.

O Método Multicritério de Apoio à Decisão Construtivista é dividido em três fases

Estruturação do Modelo

Nessa fase, o contexto do problema é estruturado e organizado a partir dos aspectos julgados mais relevantes pelo decisor. Os Elementos Primários de Avaliação (EPA) são constituídos de objetivos, valores e metas do decisor, bem como de ações, opções e alternativas. Para a identificação dos EPA, são realizadas reuniões de brainstorm (tempestade de ideias), em que os atores devem expressar livremente seus pensamentos e considerações, sendo que, para a presente pesquisa, os EPA foram construídos a partir das entrevistas com o próprio decisor, o que se justifica pelo fato de manter grande contato, através de reuniões permanentes, com os demais órgaos e instituições consideradas como subsistema de atores para a construção do modelo. Os conceitos construídos na etapa anterior são agrupados em áreas de preocupação e são identificadas as relações de hierarquia e de influência entre os conceitos agrupados, para a construção dos mapas de relações meios fins. A estrutura de relações de influência entre os conceitos, por áreas de preocupação é, nesta fase, convertida em uma estrutura hierárquica de valor, agregando o entendimento das preferências do decisor no modelo em construção. A figura 1 mostra a representação da Estrutura Hierárquica Primária em que são representados o Rótulo do problema, as Áreas de Preocupação e seus respectivos Pontos de Vista Fundamentais, para o modelo construído para o Estudo de Caso.

Os descritores são formados por níveis de impacto que descrevem as possíveis performances das ações potenciais através de escalas ordinais que são construídas de maneira interativa com o decisor. Ele identifica os Níveis de Referência, chamados de Nível Bom, que representa o nível acima do qual o decisor julga o desempenho como excelente, e o Nível Neutro, abaixo do qual o desempenho é comprometedor.

Avaliação

A função de valor de um descritor é usada para ordenar a intensidade de preferência do decisor entre pares de níveis de impacto ou ações potenciais. Na etapa de estruturação, são construídos os descritores, ou seja, escalas ordinais que, por não serem numéricas, precisam ser transformadas, de modo a se tornarem numéricas (cardinais). Para esta transformação, demonstrada na figura 2, o método MCDA-C busca, junto ao decisor, informações que permitam conhecer a diferença de atratividade entre os níveis de cada escala utilizando-se do software MACBETH - Measuring Attractiveness by a Categorical Based Evaluation Technique, a partir de juízos absolutos sobre a diferença de atratividade entre duas alternativas. 


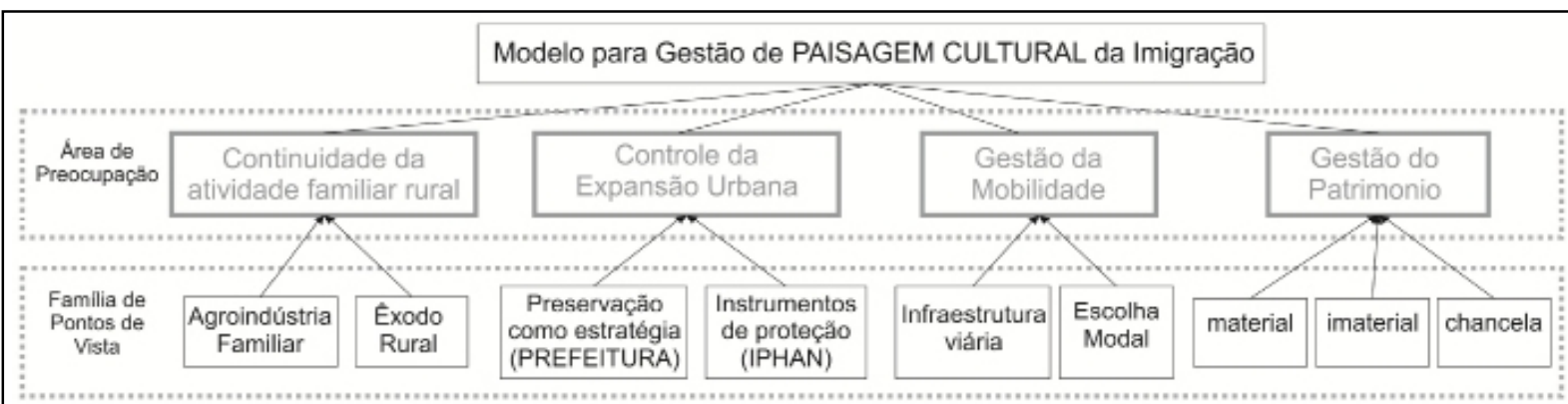

Figura 1 - Estrutura hierárquica primária identificada a partir dos conceitos. Fonte: Elaborado pelo autor.

A etapa seguinte na construção do entendimento consiste em agregar as avaliações locais de cada critério em uma avaliação global que possibilite a comparação de diferentes alternativas. As taxas de substituição são parâmetros julgados adequados pelos decisores para unificar os desempenhos dos critérios em um desempenho global, e expressam o quanto os decisores aceitam de perda de desempenho em um determinado critério, para compensar o aumento no desempenho de outro critério. Inicialmente, é necessário criar ações potenciais que representem a contribuição da passagem do nível Neutro para o nível Bom, em cada um dos critérios que se deseja determinar as taxas, assim como uma ação de referência com desempenho Neutro em todos os pontos de vista e, a seguir, ordenam-se as alternativas, o que pode ser realizado utilizando-se a Matriz de Roberts, sendo que, para isso, o decisor deverá fornecer as informações sobre as alternativas potenciais construídas segundo sua preferencia .

Com as taxas de substituição calculadas e inseridas na estrutura, elabora-se um perfil de forma gráfica, que mostra o desempenho alcançado em cada critério definido pelo modelo e possibilita a visualização do desempenho em cada critério, para ajudar nas recomendações e possíveis melhorias necessárias às ações potenciais conforme figura 3 .

A Avaliação Global permite que o decisor tenha uma visão global do desempenho das ações considerando todos os Pontos de Vista Fundamentais. O desempenho é obtido pela soma dos valores parciais, considerando as taxas de substituição de cada critério, sendo que o modelo global é definido e explicado por uma equação geral de agregação aditiva proposta por ENSSLIN et al (2010):

$\mathrm{V}(\mathrm{a})=\mathrm{W} 1 * \mathrm{~V} 1(\mathrm{a})+\mathrm{W} 2 * \mathrm{~V} 2(\mathrm{a})+$

$\mathrm{W} 3 * \mathrm{~V} 3(\mathrm{a})+\ldots . \mathrm{Wn} * \mathrm{Vn}(\mathrm{a})$ onde:

$\mathrm{V}(\mathrm{a})=$ Valor Global da Ação X

V1(a), V2(a), ... Vn(a) = Valor parcial da

Ação X nos critérios 1, 2, 3,..., n.

$\mathrm{W} 1, \mathrm{~W} 2, \ldots ., \mathrm{Wn}=$ Taxas de Substituição nos critérios $1,2,3, \ldots, \mathrm{n}$.

$\mathrm{n}=$ número de critérios do modelo

Recomendações

Finalmente, a Fase de Recomendação objetiva demonstrar o processo de geração de

\begin{tabular}{|c|c|c|c|c|c|c|c|c|}
\hline \multirow{2}{*}{$\begin{array}{c}\text { DESCRITOR: } \\
\text { Orgãos Municipais } \\
\text { Periodicidade de } \\
\text { açōes com secretarias } \\
\text { municipais de } \\
\text { agricultura para } \\
\text { criaçăo e aplicaçăo de } \\
\text { legislaçăo municipal } \\
\text { adequada }\end{array}$} & \multicolumn{7}{|c|}{$\begin{array}{c}\text { Tela do software MACBETH - Measuring Attractiveness by a } \\
\text { Categorical Based Evaluation Technique, no qual è obtida a } \\
\text { diferença de atratividade entre os niveis de cada escala, a partir das } \\
\text { consideraçôes do decisor. }\end{array}$} & \multirow[t]{2}{*}{$\begin{array}{c}\text { Função de } \\
\text { Valor obtida } \\
\text { com o } \\
\text { Macbeth }\end{array}$} \\
\hline & 圆 & Men & Tri & Sem & Anu & Ine & $\begin{array}{l}\text { Escala } \\
\text { actual }\end{array}$ & \\
\hline Mensal & Men & nula & fraca & moderada & mt. forte & extrema & 122 & 122 \\
\hline Trimestral & Tri & & mula & moderada & positiva & extrema & 100 & 100 \\
\hline Semestral & Sem & & & nula & forte & extrema & 67 & 67 \\
\hline Anual & Anu & & & & nula & extrema & 0 & 0 \\
\hline Inexistente & Ine & & & & & nula & -133 & -133 \\
\hline
\end{tabular}

Figura 2 - Transformação do descritor “Órgãos Municipais” em Função de Valor por meio do método Macbeth. Fonte: Elaborado pelo autor. 


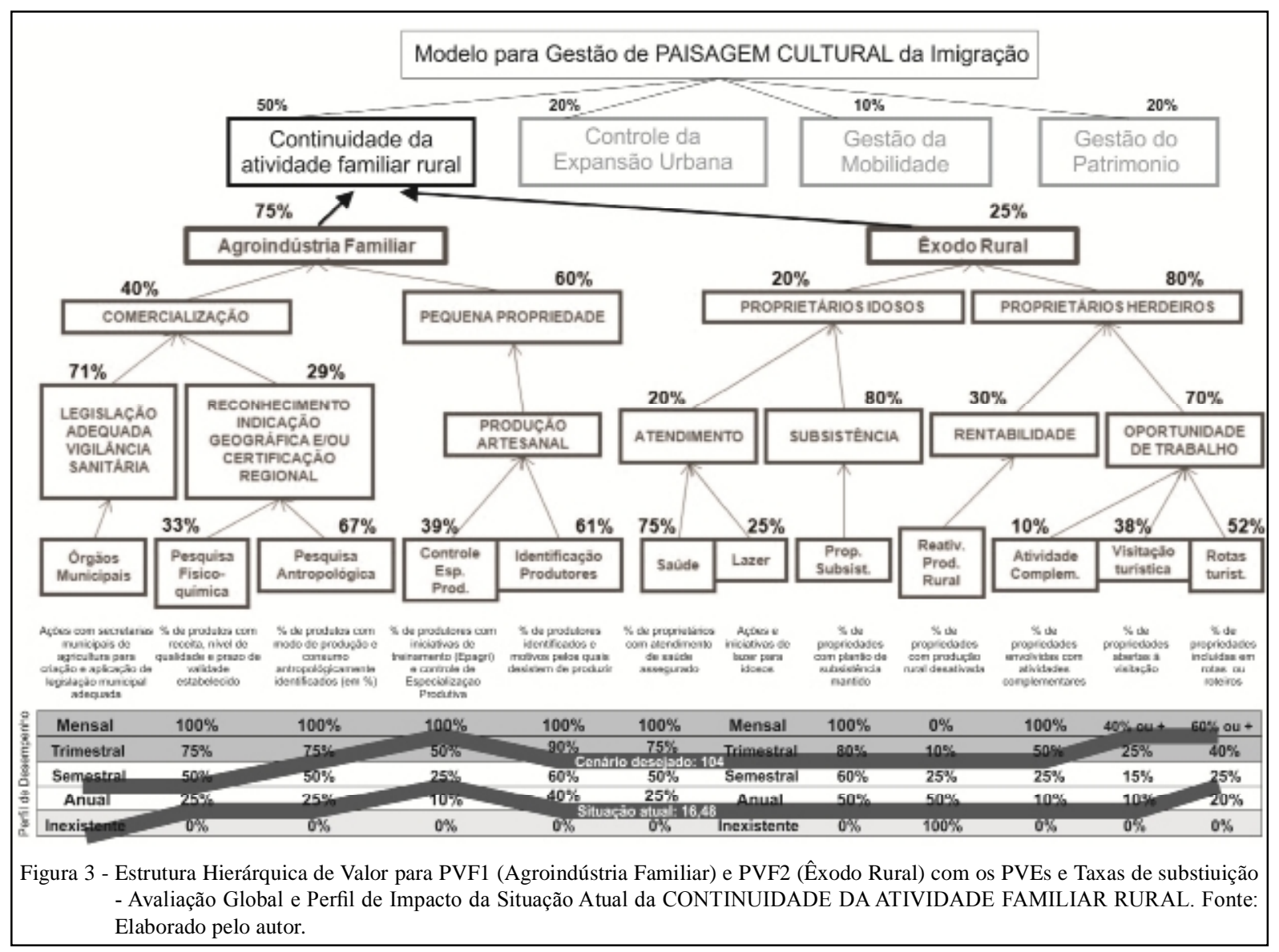

possibilidades potenciais que visam melhorar $o$ desempenho da gestão para a Preservação da Paisagem Cultural de Imigração alemã, no caso deste artigo, em relação ao estado atual da área de preocupação Continuidade da Atividade Familiar rural, com ênfase nos critérios relacionados à produção do Kochkaese. $\mathrm{O}$ processo de geração de alternativas de recomendação é feito com base nos descritores cujo desempenho não atendeu às expectativas do(s) decisor(es).

\section{RESULTADOS}

As alternativas para o Kochkaese

Os resultados obtidos na Avaliação Global e Perfil de Impacto da Situação Atual com o modelo MCDA-C, quanto à CONTINUIDADE DA ATIVIDADE FAMILIAR RURAL demonstram que, para o decisor, este é o aspecto de maior impacto para a Gestão da Paisagem Cultural, representando 50\% em relação às outras áreas de preocupação (Controle da Expansão Urbana, Gestão da Mobilidade e Gestão do Patrimônio). Obteve-se o valor de $-16,48$ para a situação atual e de 104 para o cenário desejado pelo decisor para os próximos 10 anos, prazo para reavaliação da chancela. Constatou-se que o PVF Agroindústria Familiar é preponderante $(75 \%) \mathrm{em}$ relação ao Êxodo Rural (25\%), demonstrando que o principal problema enfrentado pela gestão é de ordem econômica, com falência da pequena propriedade familiar de policultura e consequente esvaziamento das áreas rurais e desvalorização da produção tradicional que levam tais áreas a transformarem-se em "periferia urbana".

Um dos principais problemas está relacionado com a produção artesanal do Kochkaese, sendo que, o Ministério da Agricultura, Pecuária e Abastecimento (MAPA) publicou a Instrução Normativa $n^{\circ}$ 57, no Diário Oficial da União (DOU) de 16 de dezembro de 2011, com critérios bem mais flexíveis para comercialização do queijo artesanal, possibilitando, a venda do produto fresco para outros estados e até mesmo para o exterior, definindo requisitos para a produção, garantindo sua qualidade e atendendo aos aspectos de sanidade e saúde pública. Segundo a Instrução Normativa, no caso da produção artesanal de queijos com maturação inferior a 60 dias, fica liberada para "as queijarias situadas em regiões certificadas ou tradicionalmente reconhecidas e em 
propriedade produtora de leite cru com status livre de tuberculose, brucelose e controle de mastite" (BRASIL, 2011).

O modelo multicritério aponta que, além da adequação da legislação de vigilância sanitária, o Reconhecimento através de Indicação Geográfica (IG) do INPI ou de uma Certificação Regional pode ser a alternativa para a comercialização e saída do Kochkaese da clandestinidade atualmente praticada, sendo necessárias pesquisas físico-químicas e antropológicas sobre a produção de tal queijo.

Embora na América Latina - e particularmente no Brasil - seja recente, especialmente no que se refere às políticas públicas, a atenção conferida ao Reconhecimento de produtos de fabricação artesanal com identidade cultural, no continente europeu o debate sobre experiências neste campo, principalmente a partir de sistemas de Indicação Geográfica, já tem uma longa trajetória percorrida, com destaque especial para o caso francês dos produtos de terroir (RAUTENBERG et al., 2000). A IG constitui-se em uma das formas especiais de proteção aos produtos, ligada a uma especialidade do direito, a propriedade intelectual, e assegurada por várias convenções internacionais. Segundo a Lei da Propriedade Industrial $\mathrm{n}^{\mathrm{o}}$ 9.279, de 14/05/1996, a indicação geográfica no Brasil compreende duas modalidades: a indicação de procedência e a denominação de origem, tendo sido delegado ao Instituto Nacional de Propriedade Industrial (INPI), a responsabilidade pelo estabelecimento das condições de registro, o que é tratado na Resolução n⿳⺈ 75/2000 do INPI (INPI, 2000).

Emtermos debenefícios, odesenvolvimento local/regional, as indicações geográficas podem potencializar mudanças socioeconômicas em diferentes setores produtivos ligados diretamente ou indiretamente à indicação de procedência estabelecida e pode conferir a certos produtos, como no caso dos vinhos (FALCAO \& REVILLION, 2010), maior confiabilidade e servir como indicador de qualidade junto a grupos de consumidores específicos. A IG possibilita a concretização do reconhecimento de um lugar como originário de um determinado produto que se encontra impregnado de cultura garantindo, não apenas o mercado para o produto, mas a permanência de seus produtores no lugar, cultivando hábitos passados de pai para filho e garantindo o desenvolvimento sustentável daquelas comunidades que, muitas vezes, poderiam vir a se esvaziar com a ida dos filhos para a cidade e a perda completa da memória cultivada ao longo de gerações (VALENTE et al, 2012).

\section{CONCLUSÃO}

É histórica a proteção, por meio de normas e leis internacionais, de produtos cujas qualidades diferenciadas são estreitamente vinculadas às técnicas produtivas tradicionalmente praticadas e ao efeito das características naturais do território onde são produzidos.

No Brasil, tanto o tema da proteção de tais produtos quanto o do conceito de Paisagem Cultural são recentes e as diferentes referências apresentadas demonstram que existe um longo caminho a ser percorrido que dependerá de um maior investimento em recursos humanos, técnicos e financeiros por parte das instituições competentes. A Pesquisa evidenciou que no caso da Paisagem Cultural de Imigração Alemã em Santa Catarina em que há a produção do Kochkaese e tal produção vem sendo constantemente notificada pela Vigilância Sanitária, tanto o Reconhecimento através de Indicação Geográfica (IG) do INPI quanto a Certificação Regional podem contribuir para a Preservação do Patrimônio além de representar uma oportunidade para os agricultores.

\section{REFERÊNCIAS}

BRASIL. Lei no 9279 de 14 de maio de 1996. Regula direitos e obrigações relativos à propriedade industrial. Diário Oficial da República Federativa do Brasil, Brasília, DF, 15 maio, 1996.

BRASIL. Portaria ${ }^{\circ} 127$, de 30 de abril de 2009. Estabelece a Chancela da Paisagem Cultural. Diário Oficial da União, Brasília, 5 maio 2009. Seção 1, p. 17.

BRASIL. Ministério da Agricultura, Pecuária a Abastecimento. Instrução Normativa $\mathrm{n}^{\circ}$ 57. Regulamenta a produção de queijo artesanal de regiões tradicionais com leite cru e maturação inferior a 60 dias. Diário Oficial da União, Brasília, 16 de dezembro de 2011.

ENSSLIN, L. et al. Avaliação do desempenho de empresas terceirizadas com o uso da metodologia multicritério de apoio à decisão - construtivista. Pesquisa Operacional, v.30, n.1, p. 125-152, 2010. ISSN 0101-7438. Disponível em: <http://www. scielo.br/pdf/pope/v30n1/07.pdf >. Acesso em: 12 jan. 2012. doi: 10.1590/S0101-74382010000100007

FALCAO, T. F. e REVILLION, J. P. P.. A indicação geográfica de vinhos finos segundo a percepção de qualidade de enófilos. Ciência Rural. v.40, n.2, p. 423-428, 2010. ISSN 0103-8478. Disponível em: 〈http://www.scielo.br/pdf/cr/v40n2/a440cr1911.pdf>. Acesso em: 17 jun. 2012. doi: 10.1590/S0103-84782010000200031.

INPI. Instituto Nacional da Propriedade Industrial. Resolução no 75 de 28 de novembro de 2000 . Estabelece as condições para o registro das indicações geográficas. Rio de Janeiro.

Lei Complementar do Estado de Santa Catarina $\mathrm{n}^{\circ}$ 495/2010. Disponível em: <http://server03.pge.sc.gov.br/ LegislacaoEstadual/2010/000495-010-0- 2010-001.htm>. Acesso em: 15 jun. 2012.

Ciência Rural, v.44, n.11, nov, 2014. 
NEUMANN, P. S.; LOCH, C. Legislação Ambiental, Desenvolvimento Rural e Práticas Agrícolas. Ciência Rural, v. 32, n. 2, p. 243-249, 2002. Disponível em: <http://www.scielo.br/pdf/ cr/v32n2/a10v32n2.pdf>. Acesso em: 17 jun. 2012. doi: 10.1590/ S0103-84782002000200010.

RAUTENBERG, M. (Dir.). Campagnes de tous nos désirs: Patrimoine et nouveaux usages sociaux. Paris: Editions de la Maison des sciences de l'homme, Coll. Ethnologie de la France, $2000.191 \mathrm{p}$

SULZBACHER, A. W. ; DAVID, C. de. Alternativas para o Espaço Rural: importância de compatibilizar políticas públicas com saberes locais. Campo-Território: Revista de Geografia Agrária, v.3, p.14-37, 2008. Disponível em: <http://www.seer.ufu. br/index.php/campoterritorio/article/view/11838>. Acesso em: 17 jun. 2012

SULZBACHER, A. W. et al. No coser da especialização produtiva, os impactos sociais da consolidação da agroindústria familiar rural. In: ENCUENTRO DE GEOGRAFOS DA AMERICA LATINA, 12, 2009. Montevideo. Anais. v. XII. p. 1-15.

UNESCO - Convenção sobre a Proteção do Patrimônio Cultural e Natural. Paris, 1992.

VALENTE, M. E. R. et al. Indicação geográfica de alimentos e bebidas no Brasil e na União Européia. Ciência Rural, v. 42, n.3, p. 551-558, 2012. ISSN 0103-8478. Disponível em: <http://www. scielo.br/pdf/cr/v42n3/a7712cr5407.pdf >. Acesso em: 17 jun. 2012. doi: 10.1590/S0103-84782012000300027. 